\title{
As organizações na Internet: um estudo comparativo
}

\author{
Cleusa Maria Andrade Scroferneker ${ }^{1}$ \\ PPGCOM/PUCRS \\ scrofer@pucrs.br
}

\begin{abstract}
Resumo: A uso da Internet pelas organizações passou representar a possibilidade de estreitamente de relações com seus diversos públicos. Nos sites as organizações se apresentam, ser tornam 'visíveis', se dão a conhecer. Preocupam-se com o seu conteúdo, mas também com a forma como este é apresentado, buscando atender aos diferentes perfis de seus usuários. A localização dos links, a posição da logomarca, a utilização de slogan, a seleção das cores, a existência (ou não) de animação, a presença de fotos, propaganda, e janelas pop-up, e os serviços $e$ as formas de interatividade disponibilizadas assumem relevância nesse meio de comunicação. O presente texto é o resultado de uma pesquisa que analisou a 'visibilidade' organizacional nos sites, especificamente das homepages de empresas e de universidades.
\end{abstract}

Palavras-chave: Internet, organizações, comunicação organizacional

\begin{abstract}
The use of the Internet by organizations has become a new possibility they now have to narrow their relationship with their diverse publics. In their sites th e organizations present themselves, become visible. They worry about the contents and the form of their pages which they assume must fit the different profiles of their publics. That means they are very much concerned with the placement of links, the positioning of logos, the appropriateness of their slogans, the selection of colors, the convenience of using animation, the use of photographs, the presence of propaganda, and the deployment of popup windows. Moreover, interactive services and the form they assume in this communicational context are highly relevant. The present text results from a research which investigated the visibility of the organizations' sites specially of homepages of businesses and universities, along the lines mentioned above.
\end{abstract}

Key words: Internet, organizations, organizational communication

${ }^{1}$ Doutorado em Ciências da Comunicação pela Escola de Comunicação e Artes da Universidade de São Paulo - ECA/USP e Professora Titular da Faculdade de Comunicação Social da Pontifícia Universidade Católica do Rio Grande do Sul FAMECOS/PUCRS. 
Resumen: El uso de la Internet por las organizaciones pasó a representar la posibilidad de estrechamiento de relaciones con sus diversos públicos. En los SITES las organizaciones se presentan, se hacen visibles, se hacen conocidas. Se preocupan con su contenido, pero también con la forma como este es presentado, buscando atender a los diferentes perfiles de sus usuarios. La localización de los links, la posición de logomarca, la utilización de slogan, la selección de los colores, la existencia (o no) de animación, la presencia de fotos, propaganda, y ventanas pop-up, además de los servicios y las formas de interactividad puestas a disposición, asumem relevancia en ese medio de comunicación. El presente texto es el resultado de una pesquisa que analisó la 'visibilidad' organizacional en los sites, especificamente de las homepages de empresas y de universidades.

Palabras-clave: Internet, organizaciones, comunicación organizacional

Resumé: L'usage d'Internet par les Organisations peut signifier la possibilité d'approfondir les rapports avec leurs divers publics. Dans leurs sites les organisations peuvent se présenter, se montrer, devenir visibles et se donner à connaître. Dans ce sens-là elles font attention au fond, à ce qui est dit, mais aussi à la forme de présentation des informations, ayant par but de toucher les différents usagers de la toile. Il faut tout prévoir car la localisation des "links », la place du logo, l'utilisation d'un slogan, le choix des couleurs, le recours (oui ou non) à des animations, les photos, la publicité, les fenêtres «pop-up », les services et les formes " d'interactivité 》 disponibles ont énormément d'importance dans ce média. Ce texte-ci est le résultat d'une recherche sur la visibilité des organisations sur le web à partir de l'analyse de quelques homepages d'entreprises et d'universités.

Mots-clé: Internet, organizations, communication d'organisation 


\section{Introdução}

Vive-se em um mundo de simultaneidades e de antagonismos, de relações voláteis e intensas, de economias globalizadas e globalizáveis, de organizações lucrativas, responsáveis socialmente, que ora se humanizam, para desumanizarem-se logo adiante. Estimulam-se indivíduos organizacionais ‘sem rosto' (ou seria outro rosto?), a virtualização das relações e dos diálogos. É a "era das solidões interativas" segundo que Wolton (2003. p.103).

O impacto das novas tecnologias é incontestável, “[...] estão em todos os lugares, no trabalho, no lazer, nos serviços, na educação..." (WOLTON, 2003, p.107). Nessa mesma linha de raciocínio, Tapscott (1999, p.19) entende que “ Os novos meios estão mudando a forma de fazer negócio, de trabalhar, de aprender, de brincar e até mesmo de pensar.”

Para Bueno (2003, p.49) “[...] com as novas tecnologias, dentre as quais a Internet tudo muda. Castells (2003, p.255) afirma tratar-se de "um meio de comunicação, de interação e de organização social constantes". A uso da Internet pelas organizações passou a representar a possibilidade de estreitamente de relações com seus diversos públicos. Nos sites as organizações se apresentam, ser tornam 'visíveis', se dão a conhecer. Preocupam-se com o seu conteúdo, mas também com a forma como este é apresentado, buscando atender os diferentes perfis de seus usuários. A localização dos links, a posição da logomarca, a utilização de slogan, a seleção das cores, a existência (ou não) de animação, a presença de fotos, propaganda, janelas pop-up, os serviços e as formas de interatividade disponibilizadas assumem relevância nesse meio de comunicação”.

De posse de um endereço eletrônico se conhecem lugares, selecionamse roteiros de viagens, visitam-se universidades, hospitais, estúdios de cinema, empresas. Adquirem-se entradas para cinema, passagens aéreas e rodoviárias, compram-se eletrodomésticos e até automóveis, as compras do supermercado 
são colocadas no carinho, se obtêm resultados de exames laboratoriais, se realizam matrículas escolares. Acredita-se que os sites, a partir das suas homepages, estão se tornando em importantes canais de relacionamentos. Para Bueno (2003, p.52) "As organizações modernas já perceberam que relacionamento é a palavra-chave".

O presente artigo apresenta os resultados de uma pesquisa realizada no período compreendido entre 2004/2005, que objetivou analisar a 'visibilidade' (e usabilidade) organizacional dos sites, e especialmente das homepages de cinco empresas consideradas pelo Guia Você s/a Exame como "As Melhores para Você Trabalhar"2. Objetiva, igualmente, comparar com os resultados de pesquisa realizada no período compreendido entre 2001-2003 envolvendo a análise dos sites das universidades brasileiras, sob o título $A$ Universidade na Internet: um estudo comparativo dos sites das universidades brasileiras3.

Foram selecionadas empresas de segmentos diferentes com o intuito de avaliar se o fato de pertencer a um determinado segmento influenciaria os 'cuidados' em relação aos seus sites, especialmente suas homepages. Essas empresas tinham em comum localizar-se (sede e/ ou escritório de representação) na Região Metropolitana de Porto Alegre. Foram utilizadas duas edições do referido Guia Edição Especial 2003 / 2004. A utilização destas duas edições tornou-se necessária, pois houve mudanças nos critérios propostos pela revista, alterações significativas no ranking geral e mudanças internas das empresas estudadas.

\footnotetext{
${ }^{2}$ A pesquisa contou com o apoio da Fundação de Amparo à Pesquisa do Rio Grande do Sul mediante concessão de Bolsa de Iniciação Científica - FAPERGS - Bolsista Ana Paula Tormen.

${ }^{3}$ A pesquisa também contou com o apoio da Fundação de Amparo á Pesquisa do Rio Grande do Sul mediante concessão de Bolsa de Iniciação Científica - FAPERGS -

Bolsista Patrícia Câmara Rossi e foi apresentada no Núcleo de Pesquisa em Relações Públicas e Comunicação Organizacional do XXVII Congresso da INTERCOM realizado em 31 de agosto a 03 de setembro de 2004, na Pontifícia universidade Católica do Rio Grande do Sul - PUCRS.
} 
No ano de 2003 havia um critério de seleção das 10 Melhores que permaneceu em 2004, considerando que somente entrariam no ranking aquelas empresas presentes no Guia durante as três últimas edições. A revista era dividida em quatro categorias: “As 10 Melhores de 2003”, "Melhores em Desenvolvimento Profissional”, "Melhores em Equilíbrio (vida pessoal e trabalho)" e "Melhores em Remuneração e Benefícios". Em vista do grande número de empresas selecionadas tornou-se necessária a criação de três novas categorias, foram elas: empresas acima de 200 funcionários, empresas de 100 a 199 funcionários e empresas para a mulher trabalhar. A metodologia utilizada baseou-se em cinco valores: respeito, credibilidade, imparcialidade, orgulho e camaradagem. A metodologia utilizada considerou a organização (estrutura, produtos e/ou serviços), bem como o que pensavam os funcionários sobre a empresa, a adequação das políticas de RH, o programa de benefícios, além de mostrar tendências do que ainda poderia e deveria ser feito. Vale ressaltar que a metodologia desenvolvida nos Estados Unidos pelo consultor Robert Levering, levou em conta a opinião dos funcionários possibilitando que a empresa permanecesse ou fosse retirada do guia de acordo com o que pensavam os empregados. Essa opinião tem peso final de 65\%, com exceção da categoria “As 50 Melhores para a Mulher Trabalhar”.

Cada uma das empresas selecionadas possui suas bases bem fixadas no mercado. Por este motivo, antes de descrever com os procedimentos utilizados para desenvolver a pesquisa cabe fazer uma breve caracterização de cada empresa selecionada.

\section{Caracterização das empresas selecionadas}

A SLC Agrícola atua no mercado agropecuário e agroindustrial foi criada em 1945. A empresa faz parte do Grupo SLC Participações, fundado também em 1945 a partir da criação da Schneider Logemann \& Cia. Ltda e conta com mais quatro empresas : SLC Alimentos, Ferramentas Gerais, SLC Comercial e Hotel Ouro Verde. O Grupo SLC Participações contava à época da 
pesquisa com mais de 2.300 funcionários, e tem seus princípios baseados na preocupação de colaboradores, familiares e comunidade onde está inserida. As condições de trabalho, qualidade de vida dos funcionários e as relações interpessoais são a base do crescimento econômico da SLC Participações. A SLC Agrícola possui oito fazendas distribuídas em cinco estados brasileiros, e sua sede está localizada em Horizontina (RS) cidade que abrigou uma das fazendas pioneiras juntamente com a cidade de Tucunduva(RS) A empresa conta com cerca de 127 mil hectares de área própria, sendo que 100 mil hectares destinam-se à agricultura intensiva e tecnificada. (www.slcagricola.com.br, 2004)

A International Engines faz parte do International Engine Group, e tem como visão valores baseados no comprometimento, liderança, crescimento, preservação, agilidade e inovação. A empresa é líder na fabricação de motores a diesel, e possui em sua lista de clientes, empresas como Ford, General Motors, Land Rover, AGCO, Matra, Cross Lander e SDMO. A International Engines possui unidades de produção em Canoas e Córdoba (Argentina), além de um Centro de Tecnologia e Negócios em São Bernardo do Campo - SP. Esses motores são exportados para a América do Norte e Europa. Anualmente a empresa produz 175.000 motores e até 2005 pretende investir mais US\$90 milhões em motores.(www.nav-international.com.br, 2004).

A AES , foi criada em 1981 nos Estados Unidos e pertence a AES Corporation, geradora e distribuidora de energia elétrica. Está presente na Inglaterra, Irlanda do Norte, Argentina, China, Paquistão e também no Brasil com a seguinte missão: "suprir necessidades mundiais de energia elétrica de forma socialmente responsável”. A essência da cultura empresarial da empresa está baseada nos seguintes princípios: integridade, justiça e responsabilidade social. No Brasil a AES surgiu a partir da privatização da Light, em 1996. No Rio Grande do Sul a empresa surge com o leilão da antiga CEEE e passa a se chamar AES SUL DISTRIBUIDORA GAÚCHA DE 
ENERGIA S.A. A organização tem como objetivo o fornecimento de energia elétrica limpa, segura e confiável a fim de suprir necessidades energéticas globais.(www.aessul.com.br, 2004)

Há 25 anos no mercado a Petroquímica Triunfo tem como missão "prover soluções para o mercado de embalagens plásticas de forma sustentável”. Até o ano de 2010 a empresa quer ser reconhecida no Cone Sul como a melhor organização em soluções de produtos, logística e outros serviços para o mercado de embalagens plásticas.. (www.ptriunfo.com.br, 2004)

A história das Lojas Renner teve início com Antônio Jacob Renner, que em 1912 fundou o grupo A J Renner, em Navegantes. Nessa época a loja vendia apenas roupas mais resistentes ao frio da região sul, como capas de lã e capas do vestuário masculino. Hoje as Lojas Renner possuem 58 lojas espalhadas pelo Brasil, onde o encantamento é a base da realização dos funcionários. A missão das lojas Renner é “comercializar produtos de moda com qualidade a preços competitivos e excelência na prestação de serviços, conquistando a liderança, sempre orientado pelo mercado.” .Em 1965, houve a constituição das Lojas Renner S/A e dois anos mais tarde, em 1967, tornou-se uma empresa de capital aberto4. (www.lojasrenner.com.br, 2004)

\section{Dos procedimentos metodológicos}

Em relação aos procedimentos metodológicos foi uma pesquisa exploratório-descritiva (GIL, 1999) desenvolvida mediante técnicas de levantamento bibliográfico e análise de usabilidade tomando como referência os critérios propostos por Nielsen e Thahir (2002). A pesquisa exploratória se justifica na medida que é "desenvolvida com o objetivo de proporcionar uma visão geral, do tipo aproximativo sobre determinado fato. [...] é realizada especialmente quando o tema escolhido é pouco explorado e torna-se difícil

\footnotetext{
${ }^{4}$ Em 22/12/98 o controle acionário da empresa é assumido pela J.C.Penney Brazil Inc., através da sua subsidiária J.C.Penney Brasil investimentos Ltda.
} 
sobre ele formular hipótese precisa e operacional” (GIL, 1999, p. 43). A pesquisa descritiva, por sua vez, "têm como objetivo primordial a descrição das características de determinada população ou fenômeno ou o estabelecimento de relações entre variáveis" (idem, p.44). Ainda de acordo com Gil (1999, p.44) “ As pesquisas descritivas são, juntamente com as exploratórias, são as que habitualmente realizam os pesquisadores sociais preocupados com a atuação prática”.

A pesquisa de usabilidade de Nielsen e Thahir (2002) propõe a análise das homepages, a partir de 113 diretrizes, as quais foram agrupadas pelos autores em 25 grandes grupos: informando o objetivo do site, transmitindo informações sobre sua empresa, criação do conteúdo, revelando o conteúdo por meio de exemplos, arquivo e acesso ao conteúdo anterior, links, navegação, pesquisa, ferramentas e atalhos para tarefas, gráficos e animação, design gráfico, componentes da interface com o usuário, títulos da janela, URLS, notícias e comunicados à imprensa, janelas pop-up e páginas intermediárias, publicidade, boas-vindas, comunicando problemas técnicos e tratando de emergências, créditos, atualização de página, personalização, obtendo dados do cliente, favorecendo uma comunidade, datas e horas.

\section{A pesquisa propriamente dita}

Para análise dos sites, especialmente das homepages, foram seguidos os seguintes procedimentos: inicialmente foram sintetizados os critérios adotados pela Revista Exame para qualificar as organizações como "As Melhores”. Estes critérios dividem-se em dois grupos: Ambiente de trabalho (Quadro 1) e Perfil da empresa (Quadro 2): 
Quadro 1- Ambiente de trabalho

\begin{tabular}{|l|l|}
\hline \multicolumn{2}{|c|}{ AMBIENTE DE TRABALHO } \\
\hline Credibilidade & $\begin{array}{l}\text { Confiança dos funcionários na liderança. A } \\
\text { qualidade da comunicação interna, a ética e } \\
\text { a forma de divisão das tarefas. }\end{array}$ \\
\hline Respeito & $\begin{array}{l}\text { Como os funcionários são tratados, como } \\
\text { participam das decisões. Enfim, } \\
\text { reconhecimento e valorização do trabalho. }\end{array}$ \\
\hline Imparcialidade & Não haver injustiças nem favoritismo. \\
\hline Orgulho & $\begin{array}{l}\text { O prazer no que se faz, sentimento de } \\
\text { dignidade pessoal, brio, altivez. }\end{array}$ \\
\hline Camaradagem & $\begin{array}{l}\text { Boa convivência entre colegas, a qual } \\
\text { depende das relações pessoais } \\
\text { desenvolvidas. }\end{array}$ \\
\hline
\end{tabular}

Fonte: Elaborado a partir do Guia Você s/a Exame - "As Melhores Empresas para Você Trabalhar" 2003/2004.

Quadro 2 - Perfil da Empresa

\begin{tabular}{|l|l|}
\hline \multicolumn{2}{|c|}{ PERFIL DA EMPRESA } \\
\hline Benefícios & $\begin{array}{l}\text { São focadas as necessidades específicas dos } \\
\text { funcionários. O salário nem sempre é o mais } \\
\text { importante, diante de tantos outros } \\
\text { benefícios oferecidos pela empresa. }\end{array}$ \\
\hline Remuneração & $\begin{array}{l}\text { Não é avaliado somente o valor recebido } \\
\text { pelos funcionários. Nesse item entram } \\
\text { salário, bônus, participação nos resultados e } \\
\text { outras formas de reconhecimento } \\
\text { financeiro. }\end{array}$ \\
\hline Ética e Cidadania & $\begin{array}{l}\text { Para medir o nível de cidadania foram } \\
\text { analisados programas que visam o bem estar } \\
\text { da comunidade que se relaciona com a } \\
\text { empresa e vice-versa. Na ética foram } \\
\text { avaliados mecanismos oficiais e a } \\
\text { acessibilidade de acordo com os } \\
\text { funcionários. A questão da organização } \\
\text { socialmente responsável vem ganhando } \\
\text { cada vez mais importância. }\end{array}$ \\
\hline Desenvolvimento Profissional & $\begin{array}{l}\text { Oportunidades de crescimento da equipe. } \\
\text { EX: curso de reciclagem, apoio a educação } \\
\text { continuada, treinamentos... }\end{array}$ \\
\hline Equilíbrio (trabalho e vida pessoal) & $\begin{array}{l}\text { Manter esse equilíbrio garante a pontuação } \\
\text { máxima. O espaço físico acolhedor é } \\
\text { garantia de sucesso nesse quesito. }\end{array}$ \\
\hline
\end{tabular}

Fonte: Elaborado a partir do Guia Você s/a Exame - "As Melhores Empresas para Você Trabalhar" 2003/2004. 
Posteriormente foram selecionadas cinco empresas localizadas (sede e/ou escritório de representação) na Região Metropolitana de Porto Alegre (Quadro 3):

Quadro 3 - Empresas selecionadas

\begin{tabular}{|l|l|}
\hline \multicolumn{1}{|c|}{ EMPRESA } & \multicolumn{1}{c|}{ LOCALIZAÇÃO } \\
\hline AES Sul & Porto Alegre - RS \\
\hline Lojas Renner & Porto Alegre - RS \\
\hline International Engines & Canoas - RS \\
\hline Petroquímica Triunfo & Porto Alegre - RS \\
\hline SLC Agrícola & Porto Alegre - RS \\
\hline
\end{tabular}

Fonte: Elaborado a partir do Guia Você s/a Exame - "As Melhores Empresas para Você Trabalhar" 2003/2004.

Passou-se então à análise do conteúdo dos sites das empresas selecionadas, visando observar a disposição dos itens relevantes nas respectivas homepages, assim como as possibilidades de impacto destas homepages para os usuários, tendo como um dos critérios a utilização das cores, pois de acordo com Farina (1986:113), “As cores constituem estímulos psicológicos para a sensibilidade humana, influindo no indivíduo, para gostar ou não de algo, para negar ou afirmar, para se abster ou agir”. Além disso, definem ações e comportamentos, provocam, por exemplo, reações corporais e psíquicas, atraem, avisam, pois têm a capacidade de captar rapidamente e sob um domínio emotivo a atenção das pessoas, além de facilitar a memorização da mensagem. Porém, é necessário um certo cuidado com a escolha das cores, uma vez que:

A cor, além de produzir uma sensação de movimento, de expansão e de reflexão, pode também nos oferecer uma impressão estática. Mas ao relacionar uma cor a outras, dentro de um espaço bidimensional, um outro fenômeno pode acontecer. [...] os valores de uma cor se alteram quando ela passa a sofrer a 
influência de uma ou mais cores colocadas dentro de um mesmo espaço (FARINA, 1986:.91).

O impacto que cada cor causa não pode, entretanto, ser analisado isoladamente. É preciso considerar o uso que será feito deste elemento. Conforme afirma Farina (1986) há uma gama de possibilidades oferecidas pelas cores.

Seu potencial tem, em primeiro lugar, a capacidade de liberar as reservas da imaginação criativa do homem. Ela age não só sobre quem fruirá a imagem, mas, também, sobre quem a constrói. Sobre o indivíduo que recebe a comunicação visual, a cor exerce uma ação tríplice: a de impressionar, a de expressar e a de construir. A cor é vista: impressiona a retina. É sentida: provoca uma emoção. E é construtiva, pois, tendo um significado próprio, tem valor de símbolo e capacidade, portanto, de construir uma linguagem que comunique uma idéia (FARINA, 1986:26).

Nesse sentido as cores possuem certos significados que variam de acordo com a cultura e, principalmente, de acordo com a vivência de cada um. Além disso, o contraste obtido a partir de uma determinada combinação de cores é relevante, e as organizações necessitam considerar esse dado quando pensarem seus sites, e especialmente as homepages. nas suas páginas. Dependendo da combinação, que pode ser harmônica quando possuir uma parte básica da cor comum a todas as outras, ou contrastante quando as cores utilizadas forem totalmente diversas entre si, a reação poderá ser contrária à esperada. Isso significa que, de acordo com o contraste, o resultado poderá ser de harmonia e tranqüilidade, uma vivacidade que desperta interesse, ou um contraste que afasta e reprime. Dotta (2000) aponta ainda que, apesar de as páginas da Internet permitirem o uso de múltiplas cores, o ideal é não trabalhar com um layout que ultrapasse três ou quatro cores.

Em relação ao uso das cores, no caso das empresas selecionadas, constatou-se o predomínio do vermelho, que de acordo com Farina (1982) se constitui em uma cor estimulante e motivadora (Quadro 4): 
Quadro 4 - As cores das homepages da empresas selecionadas.

\begin{tabular}{|c|c|}
\hline Empresa & Cor predominante \\
\hline AES Sul & Vermelho / Azul \\
\hline Lojas Renner & Vermelho \\
\hline Petroquímica Triunfo & Vermelho \\
\hline International Engines & Amarelo \\
\hline SLC Agrícola & Verde \\
\hline
\end{tabular}

Com o intuito de verificar a periodicidade da atualização, por considerá-la um aspecto revelador da preocupação das empresas em relação aos seus usuários/clientes, durante os meses de maio/junho de2004 procedeu-se à observação dos sites, e especialmente das homepages das empresas selecionadas. Os tópicos considerados foram: notícias, slogan, barra de links lateral, menu superior, centro da homepage, cores das letras, cor de fundo da homepage, cor da fonte quando acessada, animação, ilustrações e banner.

Foi então elaborada uma tabela de observação das alterações ocorridas 5 nos meses de maio e junho de 2004,cujos resultados são apresentados no Quadro 5:

Quadro 5 - Periodicidade e atualização das homepages das empresas selecionadas

\begin{tabular}{|l|l|}
\hline \multicolumn{1}{|c|}{ Empresa } & \multicolumn{1}{c|}{ Informações relevantes } \\
\hline Lojas Renner & $\begin{array}{l}\text { As mudanças ocorrem semanalmente na } \\
\text { homepage. Características da homepage: } \\
\text { barra de informações, que varia } \\
\text { semanalmente acompanha o que está } \\
\text { anunciado no banner. }\end{array}$ \\
\hline Petroquímica Triunfo & $\begin{array}{l}\text { Cinco mudanças no item notícias no mês de } \\
\text { maio, este item foi retirado no dia 17/o5. } \\
\text { Não ocorreu nenhuma mudança no mês de } \\
\text { junho. }\end{array}$ \\
\hline
\end{tabular}

\footnotetext{
${ }^{5}$ No mês de maio foram considerados os dias 03, 07, 10, 14, 17, 21, 24, 28 e 31. Em junho os dias avaliados foram: 07, 11, 14, 18, 21, 25 e 28.
} 


\begin{tabular}{|l|l|}
\hline International Engines & $\begin{array}{l}\text { O item Notícias mudou apenas uma vez no } \\
\text { mês de maio e junho. }\end{array}$ \\
\hline AES Sul & $\begin{array}{l}\text { Houve três mudanças ao longo do mês de } \\
\text { maio. As duas relativas, ao item centro da } \\
\text { homepage e 1 no item ilustrações. No mês } \\
\text { seguinte, ocorreram apenas duas mudanças: } \\
1 \text { no centro da homepage e } 1 \text { nas ilustraçôes . } \\
\text { No mês de junho ocorreram apenas duas } \\
\text { mudanças. } \\
\text { Características da homepage: calendário do } \\
\text { mês, ilustrado com desenho feito por } \\
\text { crianças. Todo dia primeiro de cada mês é } \\
\text { modificado o calendário. }\end{array}$ \\
\hline SLC Agrícola & $\begin{array}{l}\text { Não foi constatada nenhuma mudança nos } \\
\text { dois meses }\end{array}$ \\
\hline
\end{tabular}

Tomando ainda, como referência os 113 critérios, agrupados em 25 categorias (Nielsen e Tahir , 2002) foi possível obter os seguintes resultados em relação à usabilidade:

Quadro 6 - Usabilidade das homepages das empresas selecionadas*

\begin{tabular}{|l|c|c|c|}
\hline Empresa & Usável (\%) & Não Usável (\%) & Anulado (\%) \\
\hline AES Sul & 62 & 41 & 10 \\
\hline Lojas Renner & 62 & 46 & 5 \\
\hline $\begin{array}{l}\text { Petroquímica } \\
\text { Triunfo }\end{array}$ & 49 & 51 & 13 \\
\hline $\begin{array}{l}\text { International } \\
\text { Engines }\end{array}$ & 48 & 56 & 9 \\
\hline SLC Agrícola & 52 & 51 & 10 \\
\hline
\end{tabular}

* O atendimento às 113 diretrizes configurava $100 \%$ de usabilidade.

Para a tabulação foi utilizado o critério SIM (quando a diretriz era atendida) NÃO (quando não atendida) e ITEM NÃO AVALIADO (quando a especificidade da diretriz não era atendida).

A análise constatou que três dos cinco sites eram considerados usáveis : AES Sul, Lojas Renner e SLC Agrícola. A Petroquímica Triunfo e a International Engines foram consideradas não usáveis. Tal afirmação considera o fato das três empresas terem atendido mais de 50\% das diretrizes. 
Por fim foram realizados um mapeamento e divisão gráfica das homepages segundo Nielsen e Tahir (2002).

\section{Comparando resultados}

Considerando-se que o presente artigo se constitui em relato de resultados de pesquisa realizada, julgou-se pertinente, como já indicado, em estabelecer uma comparação entre as duas pesquisas que tiveram o mesmo objeto, isto é, a análise dos sites. A primeira pesquisa sobre os sites das universidades compreendeu dois momentos distintos: no período de 2001/2002 apenas com universidades gaúchas e em 2003, com universidades brasileiras . Para a análise comparativa foram considerados os resultados obtidos em 2003 por serem mais recentes. Na análise dos sites, e especialmente das homepages, foram considerados aspectos referentes: à localização dos links, posição da logomarca, utilização de slogan, seleção das cores, existência (ou não) de animação, presença de fotos, propaganda, e os serviços e as formas de interatividade disponibilizadas.

Quanto à localização dos links nas Universidades identificou-se em $85 \%$ das homepages, links localizados à esquerda, em 10\% links localizados à direita; e em $5 \%$ dos casos links localizados no rodapé. Nas homepages das empresas analisadas 100\% dos sites possuem links à esquerda, desse universo 40\% possuem links também ao centro.

Sobre a presença de um slogan definido por Sampaio (2002, p.198) como "frase-tema de uma marca ou campanha (...) que procura resumir e definir seu posicionamento", apenas 20\% das universidades pesquisadas o possuíam. Este elemento de identificação é utilizado para chamar a atenção do usuário sobre a organização ou sobre o site, tornando mais fácil à memorização da empresa e seus objetivos. Isso significa que a maioria (80\%) das universidades não considerava tão relevante o fato de identificar-se perante a comunidade. Das cinco empresas estudadas, 4 possuíam slogan, o equivalente a $80 \%$, sendo que somente a AES Sul não possuía slogan. Pode-se 
afirmar que no caso dessas empresas, o slogan é admitido como relevante e considerado como elemento de identificação.

Em relação à posição da logomarca das universidades, em $75 \%$ das homepages analisadas localizava-se na parte superior esquerda da tela, sendo que o restante (15\%) ocupava a posição superior direita. Cabe destacar que, em $10 \%$ das páginas não havia clareza da posição da logomarca, uma vez que a universidade utilizava figuras dos dois lados da tela, o que dificultava a identificação do logotipo. No caso da logomarca das empresas constatou-se que a AES Sul, Renner, Petroquímica Triunfo e SLC Agrícola possuíam suas logomarcas na parte esquerda, enquanto a International Engines a posicionava na parte superior direita.

Sampaio (2002:186) define a logomarca como o "símbolo gráfico identificador de uma empresa ou marca”. Nielsen e Tahir (2002: 10), apontam que é preciso "exibir o nome da empresa e/ou logotipo, em um tamanho razoável e em um local de destaque", para chamar atenção de imediato quando os usuários entrarem no site. Os autores acrescentam ainda, que "geralmente, o canto esquerdo superior é o melhor posicionamento para os idiomas lidos da esquerda para a direita" (Nielsen e Tahir, 2002:10). Com base nessas colocações, pode-se afirmar que 4 das cinco empresas estudadas ao posicionarem a sua logomarca à esquerda, preocupam-se com a sua visibilidade.

Com relação às cores utilizadas nos sites das empresas, há predominância da cor vermelha em $60 \%$ das homepages, seguida pelo verde com $20 \%$ e pela combinação de preto com amarelo também em $20 \%$ dos sites, o equivalente a uma empresa.

Dentre as cores mais utilizadas nas universidades destacou-se o azul em 50\% das homepages (cor atribuída ao conhecimento, intelectualidade) seguida do preto, com $20 \%$ das ocorrências. A seguir encontrou-se o verde e o azul marinho, ambos aparecendo em 15\% das paginas. A cor laranja e branca 
constam, cada uma,em 10\% dos sites, e amarela e vermelha em 5\% das homepages.

Ao se tratar de animação, que no caso da pesquisa nas universidades apareceu principalmente (embora não exclusivamente) em banners de publicidade que possuem algum tipo de movimento, identificou-se em $65 \%$ das suas páginas contendo este tipo de artifício para chamar e prender a atenção do usuário. As outras páginas (35\%) eram estáticas. No caso das empresas todas as cinco possuíam algum tipo de animação, quase todas se configurando em banners localizados na parte superior da tela.

Em relação ao uso desta prática (animação) para atrair o usuário, Nielsen e Tahir (2002) destacam que é raro encontrar animação usada com eficiência e sugerem que se evite a animação na homepage, a não ser que ela tenha um objetivo bem definido, dado que dessa forma é possível aperfeiçoar o conteúdo on-line. Afirmam, também, que é preciso evitar a animação de elementos importantes do site, como slogan ou logotipo, pois,

A animação costuma ter um efeito hipnótico sobre os espectadores; portanto, mesmo que as pessoas parem diante dos elementos animados, é menos provável que assimilem e guardem as informações do que se as tivessem lido em um formato mais simples. (NIELSEN E TAHIR, 2002:22)

Outro critério utilizado analisado foi a presença de fotos nas homepage. Cabe, contudo, ressaltar que o significado das figuras não foi considerado. Nas páginas das 5 empresas havia a presença de fotos. Nas universidades em $75 \%$ das páginas identificou-se a presença de fotos.

A utilização de fotos e figuras para ilustrar o conteúdo pode aprimorar uma homepage, entretanto deve ser feita com cuidado já que gráficos aleatórios podem distrair os usuários do conteúdo crítico.

Nielsen e Tahir (2002:.22) lembram ainda que "gráficos podem congestionar a estrutura e retardar os tempos de download; de modo que é importante usá-los criteriosamente e editá-los para a Web”. 
Devido às características de interatividade da rede e suas inúmeras possibilidades, fez-se necessário analisar os serviços prestados pelo site, especialmente aqueles que permitem a interação do usuário, como o acesso a determinadas informações e a realização de tarefas rotineiras sem sair de casa. Conforme Dotta (2000), os serviços interativos mais comuns na rede são os mecanismos de busca (search engines), cadastros, pesquisas a banco de dados e fóruns de discussão.

A pesquisa foi realizada somente com os serviços disponíveis a partir da homepage, ou seja, de fácil acesso para a maioria dos usuários. De acordo com Dotta (2000:65) "Um site com boa arquitetura da informação terá [...] a característica de fornecer ao usuário o que ele está buscando no máximo em seu terceiro clique. O ideal é que se chegue à informação [...] já no segundo clique”.

Sobre as formas de contato, que de certa forma evidenciam a importância atribuída à comunicação(mesmo, que virtual) pelas organizações como sendo a mais utilizada (pelo menos nos sites) o Formulário on-line (Ouvidoria), apareceu em 85\% das páginas das universidades pesquisadas. Estes formulários são definidos como todo e qualquer espaço disponibilizado pela universidade para manter um contato com seu público, oportunizando espaço para criticas, sugestões, reclamações e elogios, podendo ser caracterizados como espaços de oralidade (SCROFERNEKER, 2001), mesmo que virtualizados.

Em seguida, vem o telefone e o e-mail, fazendo parte, respectivamente, de $75 \%$ e $70 \%$ das homepages estudadas. $O$ endereço e o fax são disponibilizados por $60 \%$ e $45 \%$ das universidades. Ramais telefônicos e Webmaster surgem em 20\% e 15\% dos casos analisados, respectivamente. A Intranet é disponibilizada em 10\% dos sites, e a Central de Atendimento em $5 \%$. 
Nas empresas analisadas, todas possuíam o Fale Conosco. Apenas a AES Sul oferecia a Ouvidoria e a opção "Search" era dada apenas pela Petroquímica Triunfo.

Foi igualmente analisada a presença de propaganda e publicidade nas homepages. Como citado anteriormente, os anúncios que aparecem na rede recebem o nome de banner. No caso das universidades possuíam esta particularidade 70\% das páginas. Sobre o espaço destinado à publicidade, que apresenta, muitas vezes, alguma forma de animação, Nielsen e Tahir (2002) recomendam que os anúncios sejam mantidos nas bordas das páginas e apareçam da forma o mais discreta possível, para não serem confundidos com o conteúdo central da homepage. Dentre os anúncios feitos pelas universidades destacam-se cursos de especialização, vestibular, avaliação institucional, seminários e olimpíadas.

Nas empresas 60\% possuíam propaganda institucional (AES Sul, Renner e International Engines), enquanto 40\% não tem nenhum tipo de propaganda (Petroquímica Triunfo e SLC Agrícola).

\section{Considerações finais}

No mundo em que vivemos, onde a tecnologia se faz cada vez mais presente, o tempo é cada vez mais escasso e as atribuições pessoais cada vez mais constantes, ter acesso às informações via Internet é uma facilidade que possibilita o contato, a aproximação e até mesmo a identificação das organizações com seus diversos públicos. Acredita-se que o uso da Internet pelas organizações torna-se, um importante meio de comunicação, que necessita considerar, não somente o conteúdo do site, mas também a forma como este é apresentado, buscando atender o perfil de seus usuários.

É importante destacar que duas das cinco empresas presentes no Guia de 2003 (Lojas Renner, International Engines) não figuraram no Guia de 2004; a empresa AES Sul apesar de ter permanecido no Guia em 2004, saiu 
do ranking das “10 Melhores”. As três empresas que permaneceram no Guia em 2004, apresentavam uma proporcionalidade na porcentagem referente aos tópicos: benefícios, remuneração, ética e cidadania, desenvolvimento profissional, equilíbrio (trabalho e vida pessoal). Quanto ao fator de credibilidade das empresas: em 2003 a pontuação variou, de 3 a 4 estrelas, em quatro das cinco empresas (exceto Petroquímica Triunfo). Em 2004, a Petroquímica Triunfo apresentou uma grande melhora no item credibilidade passando de uma para três estrelas. De acordo com o Guia Você s/a Exame (2004), tal situação deveu-se ao fato de ocorrerem mais ações comunicacionais por parte da empresa. Também em 2004, a AES Sul caiu um ponto no item credibilidade, passou de quatro para três estrelas. Este fato deveu-se a uma mudança na estrutura organizacional, que passou a adotar controles mais rígidos. (GUIA VOCÊ S/A EXAME, 2004).

Acredita-se que o comportamento organizacional em relação à comunicação através dos sites, tem se revelado promissor. Tal afirmação é corroborada quando se observa a preocupação das organizações, aqui representadas pelas empresas e universidades, em relação ao aspecto 'visibilidade' (e usabilidade), revelando, com certa clareza, que já percebem a relevância dessa 'nova mídia',

As universidades, embora tenham 'descoberto', as inúmeras possibilidades dos seus sites no que tange às facilidades e agilidade nos relacionamentos com seus diferentes públicos, especialmente os alunos. ainda necessitam (re) pensar, especialmente as suas homepages, redesenhando-as para torná-las mais atraentes e 'funcionais'. As empresas, por sua vez, vem procurando atender essas exigências, considerando que os seus sites, e especialmente suas homepages podem se constituir em 'cartão de visita', na medida que oferecem ao internauta cliente ou mesmo, um visitante curioso conhecê-las e reconhecê-las como a Melhor Empresa para se Trabalhar e principalmente, fazer negócios. 


\section{Referências:}

AES SUL. Disponivel em: http:// www.aesul.com.br. Acesso em 2003/2004.

BUENO, Wilson Costa. Comunicação empresarial: teoria e pesquisa. São Paulo: Manole, 2203.

CASTELLS, Manuel. Internet e sociedade em rede. In: Por uma outra comunicação. Rio de Janeiro:Record, 2003

DOTTA, Sílvia. Construção de sites. São Paulo: Global, 2000.

FARINA, Modesto. Psicodinâmica das cores em comunicação. São Paulo: Blucher, 1986.

Guia VOCÊ S/A Exame 2003. Exame Edição Especial. As Melhores Empresas Para Você Trabalhar. São Paulo: Editora Abril, 2003.

Guia VOCÊ S/A Exame 2004. Exame Edição Especial. As Melhores Empresas Para Você Trabalhar, São Paulo: Editora Abril, 2004.

GIL, Antonio Carlos. Métodos e técnicas de pesquisa social. 5 ed. São Paulo: Atlas, 1999.

INTERNATIONAL ENGINEE. Disponível em http:// www.navinternational.com.br. Acesso em 2003/2004.

LOJAS RENNER. Disponível em: http:// www.lojasrenner.com.br. Acesso em 2003/2004.

NEVES, Roberto Castro . O clone mal feito. In: Revista EXAME, $1^{\circ}$ de maio de 2002, p. 138.

NIELSEN, Jacob, TAHIR, Marie. Homepage: 50 websites desconstruídos. Trad. Teresa Cristina Felix de Souza, Rio de Janeiro: Campus, 2002.

SAMPAIO, Rafael. Marcas de A a Z. Rio de Janeiro: Campus, 2002.

SCROFERNEKER, Cleusa Maria Andrade. Os (des) caminhos da comunicação na implantação do programa de qualidade total na universidade brasileira. In: EDUCAÇÃO BRASILEIRA, Brasília : CRUB, jan/jun.2001, v.23, n.46, pp.75-91.

TAPSCOTT, Don. (Prefácio) Promessas e perigos da tecnologia digital. In: CEBRIÁN, Juan Luís. A rede. Como nossas vidas serão transformadas pelos novos meios de comunicação. Trad. Lauro Machado Coelho. São Paulo: Summus, 1999 (Coleção novas buscas de comunicação: v. 59).

SLC AGRÍCOLA. Disponível em: http:// www.slcagricola.com.br. Acesso em 2003/2004. 
WOLTON, Dominique. Internet, e depois? Uma teoria crítica das novas mídias. Trad. Isabel Crosseti, Porto Alegre: Sulina, 2003. 